\title{
Compensatory renal growth after unilateral or subtotal nephrectomy in the ovine fetus
}

\author{
Sébastien Sammut ${ }^{1,2,3}$, Luc Behrr', Mehrak Hekmati', Marie Claire Gubler ${ }^{4}$, Kathleen Laborde ${ }^{5}$ and Martine Lelièvre Pégorier ${ }^{2,3}$
}

BACKGROUND: Clinical and experimental studies show that unilateral $(1 / 2 \mathrm{Nx})$ and subtotal nephrectomy $(5 / 6 \mathrm{Nx})$ in adults result in compensatory renal growth without formation of new nephrons. During nephrogenesis, the response to renal mass reduction has not been fully investigated.

METHODS: Ovine fetuses underwent $1 / 2 \mathrm{Nx}, 5 / 6 \mathrm{Nx}$, or sham surgery (sham) at $70 \mathrm{~d}$ of gestation (term: $150 \mathrm{~d}$ ), when nephrogenesis is active. At $134 \mathrm{~d}$, renal function was determined, fetuses were killed, and kidneys were further analyzed at the cellular and molecular levels. Additional fetuses subjected to $5 / 6 \mathrm{Nx}$ were killed at 80 and $90 \mathrm{~d}$ of gestation to investigate the kinetics of the renal compensatory process.

RESULTS: At $134 \mathrm{~d}$, in $1 / 2 \mathrm{Nx}$, a significant increase in kidney weight and estimated glomerular number was observed. In $5 / 6 \mathrm{Nx}$, the early and marked catch-up in kidney weight and estimated glomerular number was associated with a striking butterfly-like remodeling of the kidney that developed within the first $10 \mathrm{~d}$ following nephrectomy. In all groups, in utero glomerular filtration rates were similar.

CONCLUSION: Compensatory renal growth was observed after parenchymal reduction in both models; however, the resulting compensatory growth was strikingly different. After $5 / 6 \mathrm{Nx}$, the remnant kidney displayed a butterfly-like remodeling, and glomerular number was restored.

W ithin several weeks after unilateral $(1 / 2 \mathrm{Nx})$ or subtotal $(5 / 6 \mathrm{Nx})$ nephrectomy in adults, the remaining kidney increases in size in response to hyperfiltration and begins to compensate for its missing partner (1), ensuring homeostasis. Renal hypertrophy develops due to glomeruli and tubules enlargement (2-4), but as nephrogenesis is complete, there are no more nephrons formed. As single-nephron glomerular filtration rate increases $(5,6)$, the solitary kidney undergoes structural injuries increasing the risk for the development of proteinuria, hypertension, and, ultimately, renal failure $(7,8)$.

In human fetuses also, studies suggest that compensatory renal hypertrophy can develop in utero, although the placenta is the major regulator of fetal homeostasis: the size of the one functional kidney in human with either unilateral agenesis (9) or contralateral multicystic dysplastic kidney (10) has been recorded to be larger than that in normal human. Moreover, kidney ultrasound studies performed during gestation show that the renal compensation begins before birth (11). In contrast to the adult, as nephrogenesis is not complete before $36 \mathrm{wk}$ of gestation, enlargement of the remaining kidney could involve the formation of new nephrons. In this setting, each nephron may have normal dimensions with subnormal single perfusion and filtration, and the risk of glomeruli injury would be proportionately reduced. Unfortunately, in these studies (9-11), nephron number was not reported. Prevalence of unilateral renal agenesis has been reported in $0.48-0.58$ per 1,000 live births (12); a $13 \%$ decrease in renal function and a $47 \%$ increase in hypertension incidence have been reported in adult patients with unilateral agenesis (13). Although function of the remaining kidney has been shown to be stable over many years in healthy adult human kidney-transplant donors, this may not be wholly reassuring for children whose life expectancy much exceeds the period of follow-up of uninephrectomized adult.

Few experimental data are available in the developing ani$\mathrm{mal}$ and are restricted to the $1 / 2 \mathrm{Nx}$ model (14-19). The majority of these studies was performed in rodents and shows an increase in kidney weight but not in the number of newly formed nephrons. As nephrogenesis continues after birth in these species, studies were carried out in neonate animals, at the end of the nephrogenesis process and in a different setting, ex utero. One study performed in the ewe (15), a species in which nephrogenesis is very similar to humans (20) and ends before birth, showed that for the first time, renal compensatory growth was associated with an increase in nephron number, although insufficient to fully compensate for the missing kidney. The authors speculated that removing one kidney at a time when nephrogenesis is more active may have resulted in activation of unknown genes and prolonged nephrogenesis, allowing additional nephrons endowment.

To test further this hypothesis, we performed $1 / 2 \mathrm{Nx}$ in sheep fetuses earlier, yet ( $70 \mathrm{~d}$ of gestation) in the course of nephrogenesis (duration: 27-120 d of gestation; term: $150 \mathrm{~d}$ ) expecting that increase in nephron number would be more important, possibly compensating totally for the missing 
kidney. We also hypothesized that the intensity of the compensatory response may depend on the initial renal reduction and therefore compared the effects on renal development in two different models of in utero nephron mass reduction: $1 / 2 \mathrm{Nx}$ and $5 / 6 \mathrm{Nx}$. The effects of parenchymal reduction on renal development were investigated at the morphological, functional, and cellular levels when nephrogenesis is known to be complete ( $134 \mathrm{~d}$ of gestation). Additional fetuses subjected to $5 / 6 \mathrm{Nx}$ at 70 $\mathrm{d}$ of gestation were killed at 80 and 90 days, during the nephrogenesis process, to identify the mechanisms initiating the compensatory process.

In fetal kidney, Pax-2 and Wilms' tumor 1 (WT1) genes are both strongly expressed in mesenchyme at early stages and play a major role in renal development (21); it is known that Pax-2 induces cellular proliferation (22) and is also antiapoptotic (23); WT1 activity is essential for the conversion of mesenchymal cells to epithelial cells (24). During nephrogenesis, renin appears to upregulate $P a x$ - 2 expression and increases ureteric bud (UB) branching in vitro $(25,27)$. To understand the mechanism of activation involved in the compensatory renal growth observed after nephron reduction, we studied the expression of these genes in our models.

\section{RESULTS}

Body weight in fetuses subjected to nephron reduction was not different to age-matched sham animals (Tables 1 and 2). No fetal morphological abnormalities were observed.

Table 1. Physiological and functional values at $134 \mathrm{~d}$ of gestation in all groups

\begin{tabular}{|c|c|c|c|}
\hline Parameter & $\begin{array}{l}\text { Sham } \\
(n=5)\end{array}$ & $\begin{array}{l}1 / 2 \mathrm{Nx} \\
(n=5)\end{array}$ & $\begin{array}{l}5 / 6 \mathrm{Nx} \\
(n=5)\end{array}$ \\
\hline \multicolumn{4}{|l|}{ Physiological parameters } \\
\hline BW (kg) & $2.99 \pm 0.76$ & $3.27 \pm 1.02$ & $2.31 \pm 0.56$ \\
\hline Kidney weight (g) & $8.25 \pm 2.42$ & $16.2 \pm 4.76^{* *}$ & $11.00 \pm 2.92$ \\
\hline Total renal mass (g) & $16.5 \pm 4.84$ & $16.2 \pm 4.76$ & $11.00 \pm 2.93$ \\
\hline Kidney weight (g)/BW (kg) & $2.78 \pm 0.45$ & $5.13 \pm 1.09^{*}$ & $4.63 \pm 2.01$ \\
\hline $\begin{array}{l}\text { Total renal mass }(\mathrm{g}) / \\
\text { BW }(\mathrm{kg})\end{array}$ & $5.56 \pm 0.90$ & $5.13 \pm 1.09$ & $4.63 \pm 2.02$ \\
\hline \multicolumn{4}{|l|}{ Functional parameters } \\
\hline $\begin{array}{l}\text { Sodium urinary rate } \\
(\mathrm{mmol} / \mathrm{h})\end{array}$ & $0.23 \pm 0.12$ & $0.26 \pm 0.14$ & $0.34 \pm 0.34$ \\
\hline $\begin{array}{l}\text { Glucose urinary rate } \\
(\mu \mathrm{mol} / \mathrm{h})\end{array}$ & $2.54 \pm 2.20$ & $0.95 \pm 0.31$ & $1.04 \pm 0.72$ \\
\hline $\begin{array}{l}\text { Creatinine clearance } \\
(\mathrm{ml} / \mathrm{min})\end{array}$ & $1.24 \pm 0.70$ & $1.73 \pm 0.43$ & $0.84 \pm 0.20$ \\
\hline $\begin{array}{l}\text { Creatinine clearance } \\
(\mathrm{ml} / \mathrm{min} / \mathrm{kg} \text { of } \mathrm{BW})\end{array}$ & $0.38 \pm 0.17$ & $0.47 \pm 0.08$ & $0.34 \pm 0.11$ \\
\hline $\begin{array}{l}\text { Creatinine clearance } \\
(\mathrm{ml} / \mathrm{min} / \mathrm{g} \text { of kidney } \\
\text { weight) }\end{array}$ & $0.07 \pm 0.03$ & $0.10 \pm 0.02$ & $0.07 \pm 0.02$ \\
\hline
\end{tabular}

The values are expressed as mean \pm SEM.

BW, body weight; $1 / 2 \mathrm{Nx}$, unilateral nephrectomy; $5 / 6 \mathrm{Nx}$, subtotal nephrectomy.

${ }^{*} P<0.05 ;{ }^{*} P<0.01$ (vs. sham).

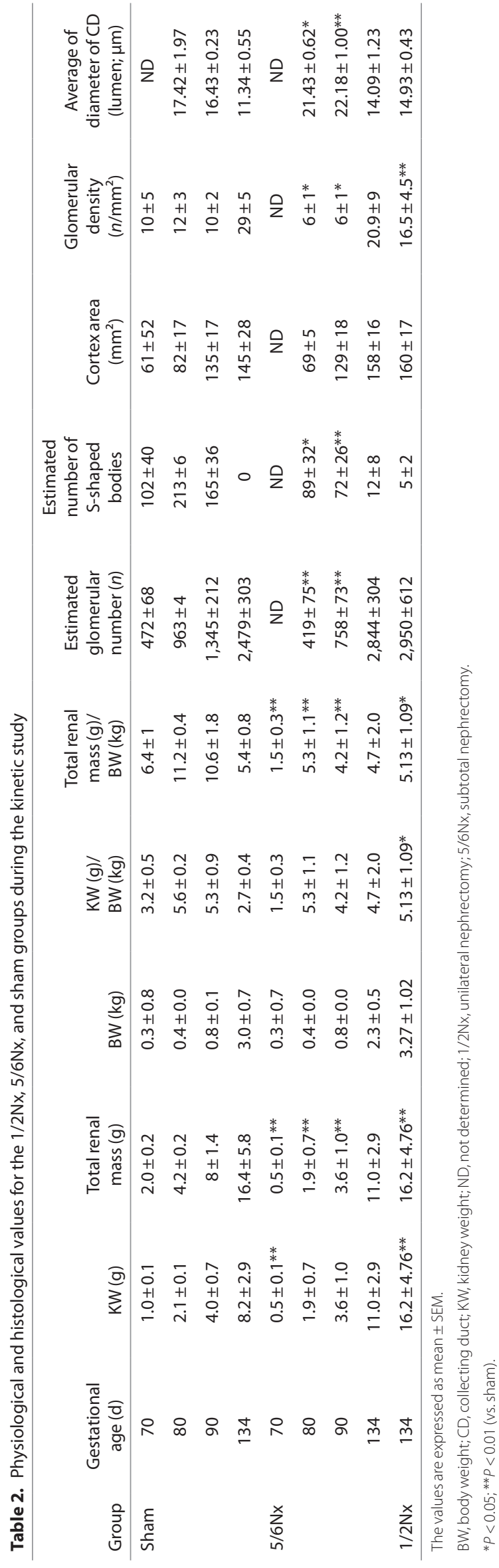




\section{Renal Sonography Studies}

Normal kidney morphology was observed in all groups at $70 \mathrm{~d}$ of gestation, before surgery.

In $1 / 2 \mathrm{Nx}$ group, the overall shape of the solitary kidney remained similar to sham group; kidney length was increased as compared with sham group at $100(34 \pm 1$ vs. $30.6 \pm 0.6 \mathrm{~mm}$, respectively; $P<0.01)$ and $134 \mathrm{~d}$ of gestation $(45.3 \pm 1.5$ vs. $36.3 \pm 1.5 \mathrm{~mm}$, respectively; $P<0.01$ ).

In $5 / 6 \mathrm{Nx}$ and sham groups, kidneys were analyzed at 70 , $80,90,100$, and $134 \mathrm{~d}$ of gestation (Figure 1). At day 80, a complete reshaping of the kidney was observed in the $5 / 6 \mathrm{Nx}$ group and persisted till the end of the study; ultrasound images showed the formation of two lobes at the incision sites. At day 70, after surgery, kidney length $(7.1 \pm 1.2 \mathrm{~mm})$ was shorter than that in sham group $(16.4 \pm 1.5 \mathrm{~mm})$ due to the $5 / 6 \mathrm{Nx}(P<0.01)$. The $5 / 6 \mathrm{Nx}$ kidney length significantly increased to $14.7 \pm 3 \mathrm{~mm}$ at day 80 and to $22.1 \pm 2.3 \mathrm{~mm}$ at day 90 but remained shorter than that in the sham group (19.2 \pm 1.7 and $28.1 \pm 1.7 \mathrm{~mm}$, respectively). Moreover, at day 100 , the kidney became longer $(33.2 \pm 0.9 \mathrm{~mm})$ as compared with sham group $(30.6 \pm 0.6 \mathrm{~mm} ; P<0.01)$ reaching $41.3 \pm 1 \mathrm{~mm}$ at $134 \mathrm{~d}$ of gestation $(36.3 \pm 1.5 \mathrm{~mm}$ in sham group; $P<0.05)$.

\section{Kidney Weight}

In $1 / 2 \mathrm{Nx}$ group, at $134 \mathrm{~d}$ of gestation, the kidney weight and the kidney weight/body weight ratio were significantly increased

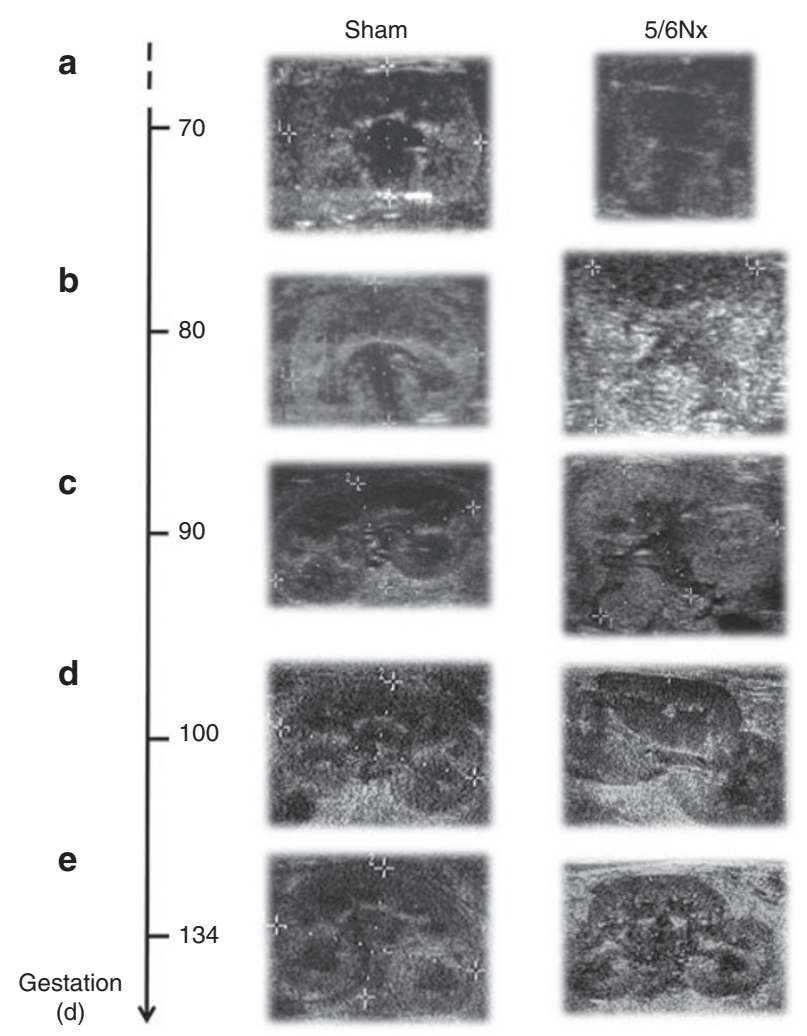

Figure 1. Sonography follow-up in $5 / 6 \mathrm{Nx}$ vs. sham group after surgery. The kidney morphology was observed by ultrasound at (a) 70, (b) 80, (c) 90, (d) 100 , and (e) 134 d of gestation. $5 / 6 \mathrm{Nx}$, subtotal nephrectomy. as compared with that in the sham group $(P<0.01$ and $P<$ 0.05 , respectively; Table 1 ).

In $5 / 6 \mathrm{Nx}$ group, the kidney weight increased rapidly, reaching sham group values as soon as $80 \mathrm{~d}$ of gestation. The kidney weight/body weight ratio was increased by a factor of 3.5 in this group, while it only increased by 1.7 in sham group. At day 90, the kidney weight in $5 / 6 \mathrm{Nx}$ group was similar to sham group. At $134 \mathrm{~d}$ of gestation, the kidney weight in $5 / 6 \mathrm{Nx}$ group tended to be higher than that in sham group (Table 2).

\section{Renal Morphology and Histology}

In $1 / 2 \mathrm{Nx}$ group, the general morphology and the corticomedullary organization of the remnant kidney (Figure 2b,e,h) were similar to sham group (Figure 2a,d,g). However, the kidney cortex was significantly thicker (1.58-fold) than that in sham group at $134 \mathrm{~d}$ of gestation $(P<0.05$; Table 2$)$. The estimated glomerular number/longitudinal section was increased after $1 / 2 \mathrm{Nx}(2,950 \pm 612$ glomeruli/longitudinal section vs. $2,479 \pm 303$ in sham group), whereas the glomerular density was significantly lower $(P<0.01)$. In both groups, glomerular diameters were larger in the deep than in the superficial cortex, as expected. No significant difference in the glomerular diameters was observed. The lumen of the collecting ducts in the remnant kidney was larger than that in sham group. No inflammatory cells and fibrosis could be observed. Rare zones of persistent nephrogenesis were present in one of five fetuses.

In fetuses subjected to $5 / 6 \mathrm{Nx}$, the kidneys exhibited a striking change in shape, displaying a "butterfly-like" growth, sprouting near the incision sites (Figures 1; 2c,f,i; and 3), in contrast with the normal kidney morphology observed in the $1 / 2 \mathrm{Nx}$ group. This feature was observed in each of the operated
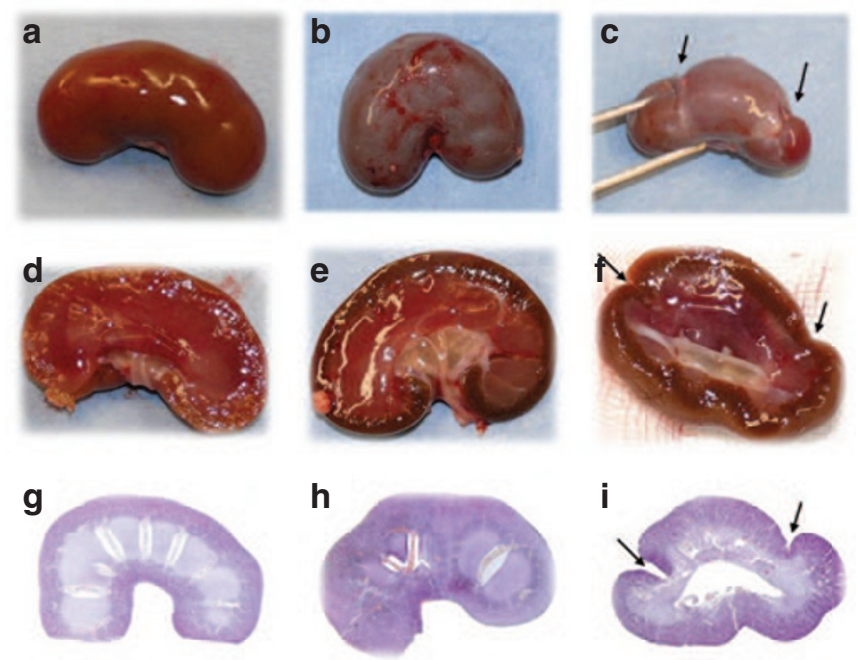

Figure 2. Kidney morphology at $134 \mathrm{~d}$ in all groups. Photographs of representative explanted kidneys, hemisected kidneys, and longitudinal sections stained with hemotoxylin, eosin, and safranin are shown for $(\mathbf{a}, \mathbf{d}, \mathbf{g})$ sham, (b,e,h) $1 / 2 \mathrm{Nx}$, and (c,f,i) 5/6Nx groups. (c,f,i) Incision sites (created at $70 \mathrm{~d}$ of gestation) are indicated by black arrows. $1 / 2 \mathrm{Nx}$, unilateral nephrectomy; $5 / 6 \mathrm{Nx}$, subtotal nephrectomy. 


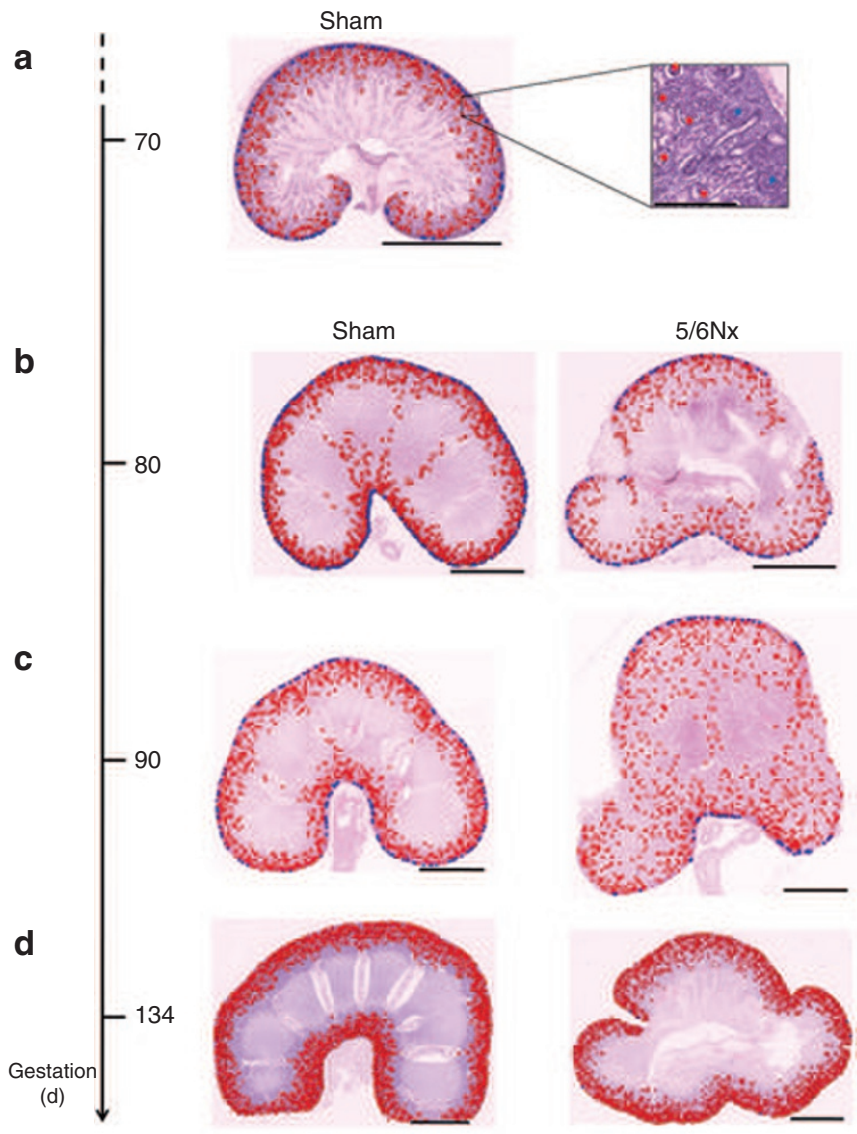

Figure 3. The distribution of glomeruli and S-shaped bodies in $5 / 6 \mathrm{Nx}$ and sham groups. Photomicrographs of representative hemisected kidney sections stained with hemotoxylin, eosin, and safranin are presented (a) at $70 \mathrm{~d}$ of gestation for the sham group and at (b) 80 , (c) 90 , and (d) $134 \mathrm{~d}$ of gestation for both the groups. Each glomerulus and $\mathrm{S}$-shaped body is represented by a red or blue point, respectively, using the nanozoomer software (Hamamatsu, Massy, France). Scale bars: $5 \mathrm{~mm} ; 100 \mu \mathrm{m}$ in inset. $5 / 6 \mathrm{Nx}$, subtotal nephrectomy.

fetuses. The newly formed poles emerged between 70 and $80 \mathrm{~d}$ of gestation and enlarged up to $134 \mathrm{~d}$ of gestation.

At day 80 , the glomeruli and the number of S-shaped bodies increased in sham kidney with a normal cortical distribution on longitudinal section (Table 2 and Figure $3 \mathrm{~b}$ ). The longitudinal sections of the kidneys clearly show the cicatricial fibrotic zone at the incision sites, characterized by the absence of nephrogenesis and mature renal structures; an important dilatation of tubules and bowman space of glomeruli were observed. The lumen of the collecting ducts in the remnant kidney was significantly larger than that in the sham group $(P<0.05)$. In the budding lobes, along the scars, marked elongation and curvature of collecting ducts were associated with a normal organization of the cortex; especially, the distribution and density of glomeruli were similar to the ones of the interscar area. During the tissue-remodeling process, $10 \mathrm{~d}$ after surgery, the mesenchyme was present in the newly developed lobes. The estimated glomerular number and S-shaped bodies were half those of sham kidney at this stage.
At day 90, the scar zone appeared limited but still observable. The glomeruli and S-shaped bodies distribution was the same as described previously (Figure $3 \mathrm{c}$ ). The estimated glomerular number was still lower than that in the sham group $(P<0.01)$. In the solitary kidney, the diameters of the collecting ducts were greater $(P<0.01)$ than that in the sham group (Table 2).

At $134 \mathrm{~d}$ of gestation, the deep notch separating the lobes was still visible at the incision sites (Figure 3d). The cortex thickness was 1.47-fold larger than that in the sham group (Table 2). All glomeruli appeared mature although S-shaped bodies were still visible in two of five fetuses of the $5 / 6 \mathrm{Nx}$ group. Glomeruli diameters were similar in both groups (Table 2). The estimated glomerular number per section in the remnant kidney reached sham values $(2,844 \pm 304$ glomeruli/longitudinal section vs. $2,479 \pm 303$ in sham group). The glomerular density tended to be lower than that in the sham group. The lumen of the collecting ducts in the remnant kidney was larger than that in the sham group. No inflammatory cells and fibrosis could be observed.

\section{Renal Function Evaluation}

At $134 \mathrm{~d}$ of gestation, the glomerular filtration rate was not different between groups whether related to fetal body weight or kidney weight in all groups (Table 1). The excretion rates of sodium and glucose were similar in all groups.

\section{Proliferation/Apoptosis Balance}

In sham group, at $134 \mathrm{~d}$ of gestation, the proliferating cell nuclear antigen (PCNA)-positive cells were scarce in the cortex and in the medulla (Figure $4 \mathbf{a}, \mathbf{b}$ ). The distribution of proliferating cells was similar in tubules and glomeruli. The percentage of terminal deoxynucleotidyl transferase nick-end labeling (TUNEL)-positive apoptotic cells was low, reaching $\sim 3 \%$ in the cortex and $6 \%$ in the medulla.

In $1 / 2 \mathrm{Nx}$ group, at $134 \mathrm{~d}$ of gestation, the PCNA expression pattern and the number of TUNEL-positive apoptotic cells did not differ as compared with sham group.

In $5 / 6 \mathrm{Nx}$ group, as in sham group, the PCNA expression was high in the condensed mesenchyme at 80 and $90 \mathrm{~d}$ (Figure $5 b, c)$. At any age of the kinetic study, the apoptotic cell number did not differ as compared with sham.

\section{Pax-2, WT1, and Renin Expression}

Pax-2. In the sham group, Pax-2 expression was observed in the collecting ducts and in the distal tubules but neither in the proximal tubules nor in the glomeruli, as expected in mature kidney at $134 \mathrm{~d}$ of gestation (Figure 4c). A low Pax-2 expression was present in Bowman's capsule.

In $1 / 2 \mathrm{Nx}$ group, at $134 \mathrm{~d}$ of gestation, $\mathrm{Pax}-2$ expression was observed in the same structures than in sham. In $5 / 6 \mathrm{Nx}$ and sham groups, at 80 and $90 \mathrm{~d}$ of gestation, Pax-2 expression was intense not only in the collecting ducts but also in the nephrogenic mesenchyme and in the S-shaped bodies (Figure $\mathbf{6 b}, \mathbf{c}$ ). At 80, 90, and $134 \mathrm{~d}$ of gestation, the distribution of Pax-2 expression in the different structures was similar in both groups. 


\section{Articles | Sammut et al.}

a

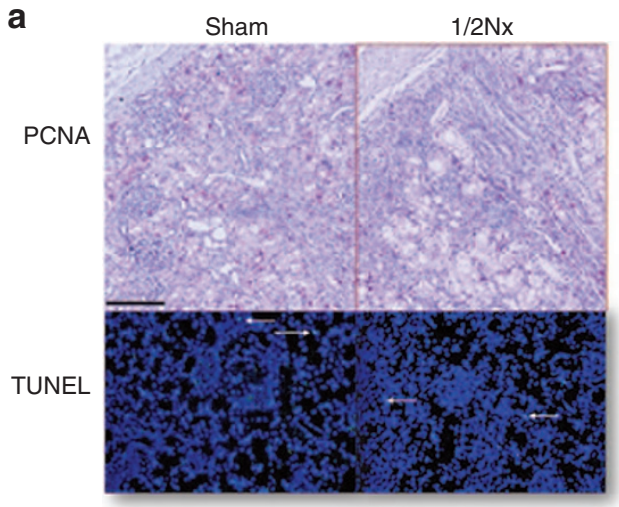

b

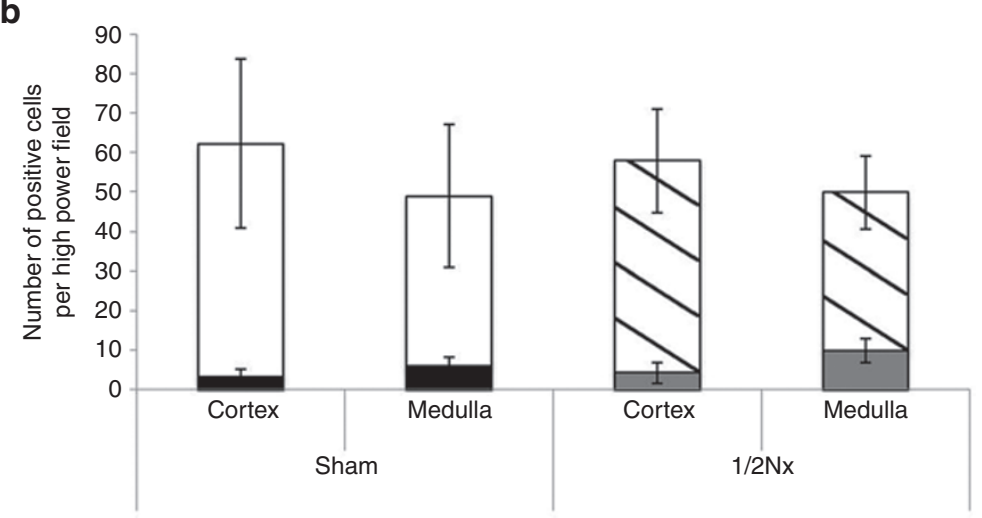

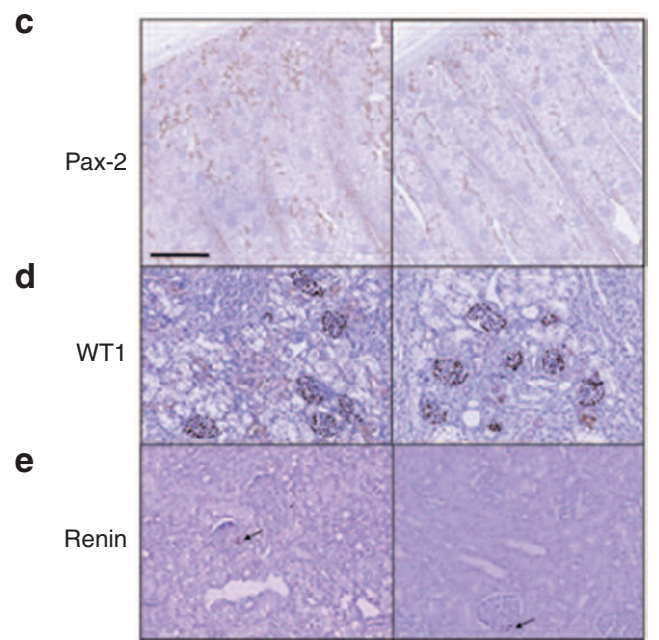

Figure 4. Proliferation/apoptosis balance and nephrogenic markers in $1 / 2 \mathrm{Nx}$ and sham groups. (a) Proliferation and apoptosis balance were investigated by PCNA and TUNEL, respectively. Positive apoptotic cell is indicated by white arrow. (b) The number of positive proliferative cells is presented either in white (sham) or hatched (1/2Nx) column; the number of positive apoptotic cells is presented either in black (sham) or gray (1/2Nx) solid. (c) Pax-2, (d) WT1, and (e) renin expressions were analyzed by immunohistochemistry. (e) Juxtaglomerular apparatus with renin expression is marked with black arrow. Scale bar: $100 \mu \mathrm{m}$ for $(\mathbf{a}, \mathbf{d}, \mathbf{e})$ and $400 \mu \mathrm{m}$ for (c). PCNA, proliferating cell nuclear antigen; TUNEL, terminal deoxynucleotidyl transferase nick-end labeling; WT1, Wilms' tumor $1 ; 1 / 2 \mathrm{Nx}$, unilateral nephrectomy; $5 / 6 \mathrm{Nx}$, subtotal nephrectomy.

WT1. In the sham group, at $134 \mathrm{~d}$ of gestation, WT1 expression was restricted to the podocytes (Figures $4 \mathbf{d}$ and 6 ). In $1 / 2 \mathrm{Nx}$ group, at $134 \mathrm{~d}$ of gestation, WT1 expression was higher than in sham group $(54 \pm 9$ positive cells/glomerulus vs. $41 \pm 8$, respectively; $P<0.01$ ). In $5 / 6 \mathrm{Nx}$ and sham groups, at $80 \mathrm{~d}$ of gestation, WT1 expression was present in the condensed mesenchyme, podocytes of newly formed glomeruli, and S-shaped bodies. No significant difference in WT1 expression was observed at day 80 as compared with the sham group. More intense podocyte staining highlighted glomeruli at $90(54.0 \pm 9$ positive cells/glomerulus vs. $38.4 \pm 2.4 ; P<0.01)$ and $134 \mathrm{~d}$ of gestation (68.9 \pm 9 positive cells/glomerulus vs. $41.0 \pm 8$; $P<$ 0.01 ), as compared with the sham group.

Renin. In all groups, at $134 \mathrm{~d}$ of gestation, renin expression was localized in the juxtaglomerular apparatus (Figures $4 \mathrm{e}$ and $6 \mathrm{~d}$ ). In $1 / 2 \mathrm{Nx}$ group, at $134 \mathrm{~d}$ of gestation, the number of positive cells in juxtaglomerular apparatus containing renin $(5.2 \pm 1)$ was higher $(P<0.05)$ than that in the sham group $(4.0 \pm 1)$. In $5 / 6 \mathrm{Nx}$ group, at $80 \mathrm{~d}$ of gestation, renin expression was clearly observed in juxtaglomerular apparatus (Figure 6b) and was similar to sham group. More intense renin expression highlighted juxtaglomerular apparatus at $90 \mathrm{~d}$ of gestation as compared with sham group (8.4 \pm 1.3 vs. $5.6 \pm 0.8$, respectively; $P<0.01)$. At $134 \mathrm{~d}$ of gestation, no difference in renin expression was observed.

\section{DISCUSSION}

Our study in the ovine fetus clearly shows that, during nephrogenesis, compensatory renal growth develops after $1 / 2 \mathrm{Nx}$ and 5/6Nx: kidney weight, kidney weight/body weight ratio, and cortex thickness increased. Although hyperplasia and hypertrophy were observed in both the models, the resulting renal compensation was strikingly different in each of the two groups with regard to the renal morphology and the magnitude of glomerular number increase.

After $1 / 2 \mathrm{Nx}$, the remnant kidney displayed a normal renal morphology. Cortex thickness was increased, glomerular density was lower, and tubules tended to be larger, suggesting that the increase in renal weight was at least in part linked to nephron hypertrophy, as described in adult and in the majority of developing animals (14-19). In addition, there was an 

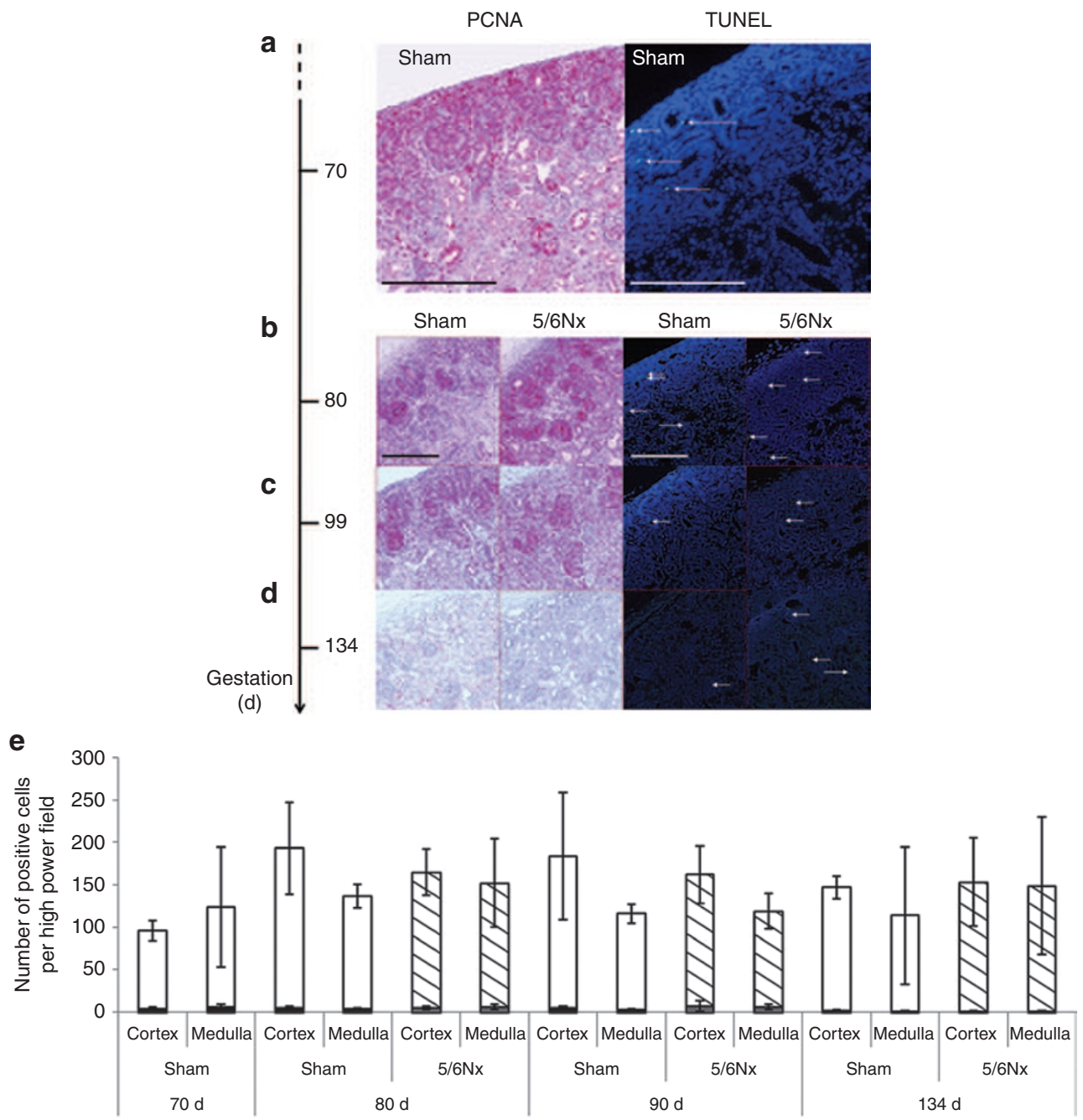

Figure 5. Proliferation/apoptosis balance in $5 / 6 \mathrm{Nx}$ and sham groups. Proliferation/apoptosis balance was investigated by PCNA and TUNEL apoptotic cell detection: (a) at $70 \mathrm{~d}$ of gestation for the sham group and at (b) 80 , (c) 90 , and (d) $134 \mathrm{~d}$ of gestation. (e) The number of positive proliferative cells is presented either in white (sham) or hatched $(5 / 6 \mathrm{Nx})$ column; the number of positive apoptotic cells is presented either in black (sham) or gray (5/6Nx) solid. (a-d) Positive apoptotic cells are indicated by white arrow. Scale bar: $200 \mu \mathrm{m}$. PCNA, proliferating cell nuclear antigen; TUNEL, terminal deoxynucleotidyl transferase nick-end labeling; $1 / 2 \mathrm{Nx}$, unilateral nephrectomy; $5 / 6 \mathrm{Nx}$, subtotal nephrectomy.

increase in glomerular number, in accordance with the results from Douglas-Denton et al. (15) who observed, in the ewe also, an increase in nephron number in fetuses subjected to $1 / 2 \mathrm{Nx}$ in utero, before the end of the nephrogenesis process. Surprisingly, although we performed nephrectomy earlier in the course of nephrogenesis ( $70 \mathrm{~d}$ of gestation) than in Douglas-Denton's study (100 d of gestation), the glomerular number compensation was not superior, whether activation of nephrogenesis is not related to the timing of renal reduction when performed before the end of nephrogenesis or whether there is a critical window when nephrogenesis is more efficient remain to be determined. Finally, the difference in glomerular counting method used must be taken into account, as the technique we developed, based on total glomerular count by section, is a less precise method than the physical dissector/fractionator method. The persistence of nephrogenic zone was a rare event (one of five fetuses) unlike the observation reported by Douglas-Denton et al. (seven of eight fetuses).
To our knowledge, it is the first time that the effects of $5 / 6 \mathrm{Nx}$ performed in utero during nephrogenesis were investigated. In these fetuses, in which only one sixth of renal tissue (i.e., onethird of the remnant kidney) was left after surgery at $70 \mathrm{~d}$ of gestation, a rapid and consistent catch-up in kidney weight was observed. As after $1 / 2 \mathrm{Nx}$, the increase in cortex thickness, the decrease in glomerular density, and the tubular hypertrophy suggest that nephron hypertrophy was also present. However, the most remarkable feature was the change in renal morphology and the striking increase in glomerular number. Contrary to fetuses subjected to $1 / 2 \mathrm{Nx}$ whose kidneys displayed uniform and harmonious compensatory renal growth, fetuses with $5 / 6 \mathrm{Nx}$ showed an intriguing pattern of renal growth, characterized by sprouting of structures at both excised renal ends, leading to a "butterfly-like" renal shape. This is the first time where such a "butterfly-like" renal growth is described during nephrogenesis, associated with an increase in the estimated glomerular number, despite initial severe renal parenchymal 


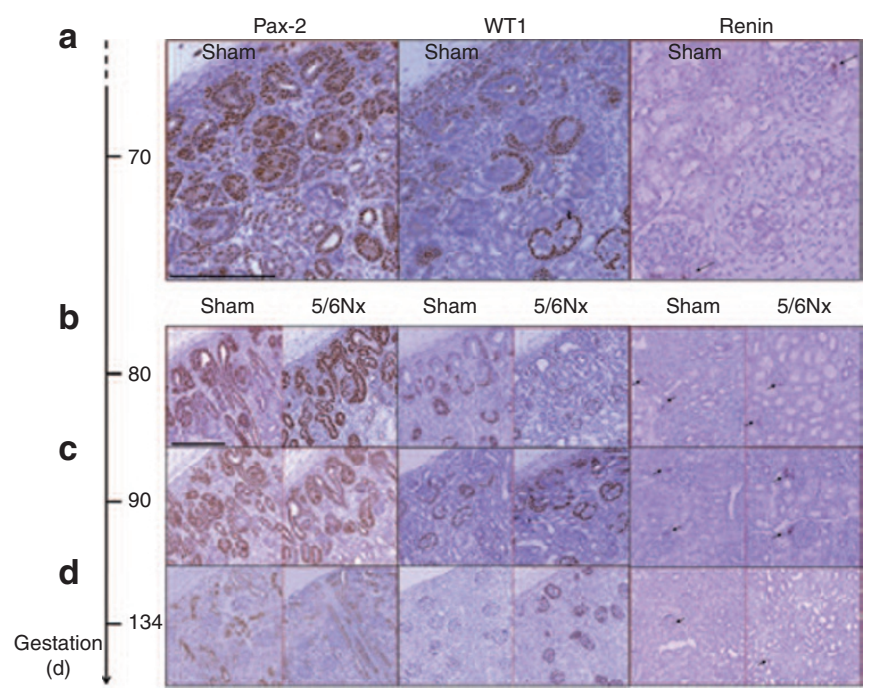

Figure 6. Nephrogenic markers in 5/6Nx and sham groups. Pax-2, WT1, and renin expressions were investigated by immunohistochemistry: (a) at $70 \mathrm{~d}$ of gestation for the sham group and at (b) 80 , (c) 90 , and (d) $134 \mathrm{~d}$ of gestation for both the groups. (a-d) Juxtaglomerular apparatus with renin expression are marked with black arrow. Scale bar: $200 \mu \mathrm{m}$. WT1, Wilms' tumor $1 ; 5 / 6 \mathrm{Nx}$, subtotal nephrectomy.

reduction. It is remarkable that this process was observed in all fetuses subjected to $5 / 6 \mathrm{Nx}$.

To better understand the mechanisms involved in nephrogenesis activation and kidney growth in 5/6Nx fetuses, we performed studies at earlier stages of renal development and observed that the process started early, being visible by sonography and histology as soon as $10 \mathrm{~d}$ after surgery. It is well known that UB induces nephrons from metanephric mesenchyme cells at its branching tips. During kidney development, the UB branches the same number of times and each tip induces nephrons (28); therefore, the number of resulting glomeruli can be a good index of normal branching process. To increase glomerular number significantly, only a small increase in efficiency of branching should be required. In $5 / 6 \mathrm{Nx}$ group, kidney remodeling and marked increase in glomerular number observed at day 134 suggested that nephrogenesis was activated after nephrectomy. The activation could have been linked to the growth and increased branching activity of sectioned UB branches. This possibility has been shown in an experimental model of cultured mice metanephroï in which existing tips were removed from stalks: Sweeney et al. (29) demonstrated that the ability to initiate branches was not restricted to tips but distributed widely and that stalks free of tip cells could initiate new branches.

However, our results show that at early stage (at $80 \mathrm{~d}$ ), no evidence of ongoing nephrogenesis (dividing UB branches) could be seen at the incision sites. This observation does not favor the hypothesis of regeneration and branching of cut stalks at the origin of nephrogenesis and directs toward the preserved parenchyma. Accordingly, budding of renal lobes was associated with elongation and curving of corresponding UB branches (Figure $3 b$ ). This observation suggests an impact of renal reduction on UB arborization at the early stage of the development of the remnant kidney regeneration.

At $134 \mathrm{~d}$ in the ewe, when nephrogenesis is complete, Pax-2 expression persists in distal tubules and collecting ducts, but WT1 in podocytes only, as reported in others species (22). Surprisingly, in both models of nephron reduction, we did not observe any striking difference in the expression of these master genes of kidney development in spite of a significant compensatory renal growth. In $5 / 6 \mathrm{Nx}$ group, the temporal expression of WT1 appeared to be delayed when compared with sham group as expression remained high at $134 \mathrm{~d}$, suggesting a slight shift at the end time of nephrogenesis. In this group, more intense renin expression was found at $90 \mathrm{~d}$ of gestation, but Pax-2 expression was similar even when renin has been reported to upregulate Pax-2 expression (26). More molecular studies are necessary to understand the mechanisms involved in the early process of the kidney growth in the context of nephron reduction during nephrogenesis.

It is still unclear regarding the signals that make the difference in the compensatory growth observed between the $1 / 2 \mathrm{Nx}$ and $5 / 6 \mathrm{Nx}$. In adult, filtration appears to be the signal that induces renal hypertrophy. In the fetus, glomerular filtration rate is low, and renal function in utero deals chiefly with urine production rather than the excretion of metabolites, which are cleared by the placenta. Therefore, it is unlikely that compensatory growth occurs from a need to maintain homeostasis of urinary filtration, at least in the model of $1 / 2 \mathrm{Nx}$. Alternatively, the stimulus may be a renotropic signal produced in response to the functioning renal mass in utero, possibly stimulated by the volume of amniotic fluid produced by the kidneys. In the case of $5 / 6 \mathrm{Nx}$, the tissue injury itself, in the context of the resumption of nephrogenesis, may be the source of the regenerative process.

In summary, our study demonstrates that compensatory renal growth can be observed when nephron reduction is performed before the end of nephrogenesis and involves both hyperplasia and hypertrophy. The magnitude of the regenerative process seems to be more dependent on renal reduction severity than timing. One of the most intriguing observations in our study when evaluating renal morphology was the "butterfly-like" renal growth at incision sites after $5 / 6 \mathrm{Nx}$. As the kinetic study showed that sprouting structures were already developed $10 \mathrm{~d}$ after surgery, further investigations performed earlier may provide better information on the molecular pathways that orchestrate the increase in branching and nephrogenesis activation. A better knowledge of the mechanisms governing fetal renal compensation may be useful to understand the factors that control the nephrogenesis process and might help to support the increase in nephron number beyond the danger zone.

\section{METHODS}

\section{Animals}

Pre-Alpes breed ewes received veterinary care, approved by the institutional ethics committee of IMM Recherche (study number: BEHR FOETAL 08-18) in compliance with the "Guide for the Care and Use of Laboratory Animals." 


\section{Study Design}

Twenty-seven of 29 ovine fetuses completed the study: 11 fetuses (7 males; 4 females) underwent $5 / 6 \mathrm{Nx}, 5$ fetuses ( 3 males; 2 females) underwent $1 / 2 \mathrm{Nx}$, and 11 fetuses ( 7 females; 4 males) were sham operated (sham). Two fetuses died before $134 \mathrm{~d}$ (each from $5 / 6 \mathrm{Nx}$ and $1 / 2 \mathrm{Nx}$ group) and were excluded from the study.

In all 27 fetuses, surgery was performed at $70 \mathrm{~d}$ of gestation. Twelve fetuses were killed during nephrogenesis at day $80(5 / 6 \mathrm{Nx}, n=3$; sham, $n=3)$ and $90(5 / 6 \mathrm{Nx}, n=3$; sham, $n=3)$ to study the kinetics of compensatory renal growth. Fifteen fetuses were killed after the end of the nephrogenesis at $134 \mathrm{~d}$ of gestation $(5 / 6 \mathrm{Nx}, n=5 ; 1 / 2 \mathrm{Nx}$, $n=5$; sham, $n=5$ ).

In all groups, renal fetal functional studies were performed before killing the fetuses at $134 \mathrm{~d}$ of gestation. At the end of the procedure, a caesarean section was performed; the fetuses were killed by injection of pentobarbital (Dolethal $60 \mathrm{mg} / \mathrm{kg}$, Vétoquinol, Lure, France) into the heart. The fetuses were removed, cleaned, and weighed. Their kidneys were removed, cleaned, weighed, hemisected through the hilus, and treated immediately for morphological studies.

\section{Unilateral and Subtotal Nephrectomy}

Ewes were treated by salbutamol sulfate $40 \mathrm{mg} / \mathrm{d}$ (Mylan, Saint Priest, France) to prevent uterine contractions. At $70 \mathrm{~d}$ of gestation, ewes were subjected to surgery under general anesthesia as described previously (20). A laparotomy was performed on the ewe to gain access to the fetuses. After midline incision, the uterine horn was briefly exposed and the fetal hindquarters palpated. An incision was made over the kidneys (random; 5/6Nx: five left kidneys and six right kidneys; $1 / 2 \mathrm{Nx}$ : two left kidneys and three right kidneys). In both the models, the renal artery, vein, and ureter were tied off, and the kidneys were excised. In the case of $5 / 6 \mathrm{Nx}$, the two poles of the remaining kidney were excised with scissors. Bleeding was prevented by finger pressure at sites of excision and by coating the cut surfaces with sterile compresses for few minutes. Renal ablation was adjusted to obtain 5/6 reduction by weight of total renal mass, assumed to be twice that of the excised kidney. The fetus was returned to the uterus and the abdomen closed. Ewes were treated by amoxicillin $15 \mathrm{mg} / \mathrm{kg}$ (Duphamox LA, Pfizer, Paris, France) intramuscular, every $2 \mathrm{~d}$ until the end of the study. Ewes were returned to the farm after surgery and had free access to food and water.

\section{Ultrasound Renal Sonography Follow-Up}

The kidney length, recorded as the maximal bipolar measurement obtained, was measured by ultrasound after surgery at 100 and 134 d of gestation, using Philips Healthcare iE33 xMATRIX Ultrasound System (Medical Systems, Eindhoven, The Netherlands). During the kinetic study, kidney lengths from sham and 5/6Nx groups were measured by sonography at 70, 80 , and $90 \mathrm{~d}$ of gestation.

\section{Renal Fetal Functional Study}

At $134 \mathrm{~d}$ of gestation, fetuses were implanted with one catheter in the femoral artery for blood sampling and another one into the bladder for urine sampling. Renal function was measured by half hourly split urine and blood collection to determine creatinine clearance (30), fractional sodium, and glucose excretion. Creatinine clearance (Ccreat) was calculated by the conventional formula: Ucreat $\times$ Vurine / Pcreat, where Ucreat and Pcreat are urinary and plasma creatinine concentrations, respectively, and $\mathrm{V}_{\text {urine }}$ is urine output $(\mathrm{ml} / \mathrm{min})$. Fractional sodium expression was calculated by $\mathrm{UNa} \times \mathrm{V} / \mathrm{PNa} \times$ Ccreat, where Ccreat is creatinine clearance, and $\mathrm{UNa}$ and $\mathrm{PNa}$ are urinary and plasma concentrations, respectively. Creatinine was measured by using the modified Jaffe kinetic technique. Sodium and glucose were measured using the Cobas Analyser (Cobas, Roche, Meylan, France).

\section{Histology}

Kidneys from all groups were hemisected throughout the hilus and fixed in a formalin solution $4 \% \mathrm{~m} / \mathrm{v}$ (Labonord, Templemars, France). Longitudinal renal cross-sections were taken throughout the hilus and embedded in paraffin. Seven-micrometer sections were cut and stained with hematoxylin, eosin, and safranin using an automated slide stainer and coverslipper (Tissue-Tek Prisma/Film, Sakura Finetek, Villeneuve
d'Ascq, France). The sections were scanned at high resolution using a slide scanner (NanoZoomer 2.0-HT, Hamamatsu, Massy, France).

An estimation of glomerular number was determined on whole longitudinal sections taken through the hilus, using a modification of McVary and Maizels method (20). Glomeruli were considered as mature when they clearly demonstrated both distinct Bowman's spaces and vascularized floculi, regardless of the glomerular width. Glomeruli and S-shaped bodies were counted one by one, scanning the entire kidney sections and using the counter from the nanozoomer software. Glomerular density was calculated as the average of glomeruli number per square millimeter.

\section{Immunohistochemistry}

Paraffin sections were dewaxed, hydrated through graded alcohols (ethanol, Labonord, Templemars, France), and rinsed in phosphatebuffered saline (GIBCO, Invitrogen, Saint Aubin, France). The sections were incubated with the specific primary antibodies: Pax-2 (Abcys Vector, Les Ulis, France), WT1 (Clone 6F-H2, Trappes, Dako France), renin (NBP1-87484, Novus Biological, Cambridge, UK), and PCNA (Clone PC10, Dako, Trappes, Dako France). Antigen staining was performed with the Envision system kit (EnVision G|2 Doublestain System, Dako, Trappes, France). Peroxydase activity was revealed with $3,3^{\prime}$-diaminobenzidine tetrahydrochloride $\left(\mathrm{DAB}^{+}\right)$, alkaline phosphatase activity with permanent red. The sections were counterstained with hematoxylin (Sigma-Aldrich, Lyon, France), rehydrated, coverslipped, and scanned. The number of PCNA-positive cells per power field was counted (magnification: $\times 40$ ) in 20 random sections.

\section{TUNEL}

Apoptosis was assessed using TUNEL assay (POD Roche Diagnostics, Meylan, France). The sections were counterstained with 4,6-diamidino2-phenylindole (Vector Laboratories, Peterborough, UK), coverslipped, and scanned. The number of positive apoptotic cells per power field was counted (magnification: $\times 40$ ) in 20 randomly selected sections.

\section{Expression of Data and Statistical Analysis}

Data are expressed as mean \pm SEM. Differences between groups were evaluated using one-way ANOVA. Comparisons of nephron number and other renal parameters were made by unpaired $t$ test. $P$ values $<0.05$ were considered statistically significant.

\section{ACKNOWLEDGMENTS}

The authors thank Nicolas Borenstein for his scientific help and the IMM Recherche and INSERM teams for their expert technical assistance.

\section{STATEMENT OF FINANCIAL SUPPORT}

This study was performed at the IMM Recherche laboratory and was supported by a grant from Association Nationale de la Recherche et de la Technologie (ANRT), Paris, France, grant 2009/1265.

Disclosure: No conflicts of interest, financial or otherwise, are declared by the authors.

\section{REFERENCES}

1. Wolf G, Neilson EG. Molecular mechanisms of tubulointerstitial hypertrophy and hyperplasia. Kidney Int 1991;39:401-20.

2. Liu B, Preisig PA. Compensatory renal hypertrophy is mediated by a cell cycle-dependent mechanism. Kidney Int 2002;62:1650-8.

3. Terzi F, Ticozzi C, Burtin M, et al. Subtotal but not unilateral nephrectomy induces hyperplasia and protooncogene expression. Am J Physiol 1995;268(5 Pt 2):F793-801.

4. Newbold KM, Howie AJ, Girling AJ, Kizaki T, Bryan RL, Carey MP. A simple method for assessment of glomerular size and its use in the study of kidneys in acromegaly and compensatory renal enlargement. J Pathol 1989;158:139-46.

5. Brenner BM, Lawler EV, Mackenzie HS. The hyperfiltration theory: a paradigm shift in nephrology. Kidney Int 1996;49:1774-7.

6. Wilson BE, Davies P, Shah K, Wong W, Taylor CM. Renal length and inulin clearance in the radiologically normal single kidney. Pediatr Nephrol 2003; 18:1147-51. 
7. Novick AC, Gephardt G, Guz B, Steinmuller D, Tubbs RR. Longterm follow-up after partial removal of a solitary kidney. N Engl J Med 1991;325:1058-62.

8. Hegde S, Coulthard MG. Renal agenesis and unilateral nephrectomy: what are the risks of living with a single kidney? Pediatr Nephrol 2009;24: 439-46.

9. Hartshorne N, Shepard T, Barr M Jr. Compensatory renal growth in human fetuses with unilateral renal agenesis. Teratology 1991;44:7-10.

10. John U, Rudnik-Schöneborn S, Zerres K, Misselwitz J. Kidney growth and renal function in unilateral multicystic dysplastic kidney disease. Pediatr Nephrol 1998;12:567-71.

11. van Vuuren SH, van der Doef R, Cohen-Overbeek TE, Goldschmeding R, Pistorius LR, de Jong TP. Compensatory enlargement of a solitary functioning kidney during fetal development. Ultrasound Obstet Gynecol 2012;40:665-8.

12. Pohl M, Bhatnagar V, Mendoza SA, Nigam SK. Toward an etiological classification of developmental disorders of the kidney and upper urinary tract. Kidney Int 2002;61:10-9.

13. Argueso LR, Ritchey ML, Boyle ET Jr, Milliner DS, Bergstralh EJ, Kramer SA. Prognosis of patients with unilateral renal agenesis. Pediatr Nephrol $1992 ; 6: 412-6$.

14. Moore ES, deLeon LB, Weiss LS, McMann BJ, Ocampo M. Compensatory renal hypertrophy in fetal lambs. Pediatr Res 1979;13:1125-8.

15. Douglas-Denton R, Moritz KM, Bertram JF, Wintour EM. Compensatory renal growth after unilateral nephrectomy in the ovine fetus. J Am Soc Nephrol 2002;13:406-10.

16. Moritz KM, Wintour EM, Dodic M. Fetal uninephrectomy leads to postnatal hypertension and compromised renal function. Hypertension 2002;39:1071-6.

17. Larsson L, Aperia A, Wilton P. Effect of normal development on compensatory renal growth. Kidney Int 1980;18:29-35.

18. Woods LL, Weeks DA, Rasch R. Hypertension after neonatal uninephrectomy in rats precedes glomerular damage. Hypertension 2001;337:342-38.
19. Bonvalet JP, Champion M, Courtalon A, et al. Number of glomeruli in normal and hypertrophied kidneys of mice and guinea-pigs. J Physiol 1977;269:627-41.

20. Edouga D, Hugueny B, Gasser B, Bussières L, Laborde K. Recovery after relief of fetal urinary obstruction: morphological, functional and molecular aspects. Am J Physiol Renal Physiol 2001;281:F26-37.

21. Ryan G, Steele-Perkins V, Morris JF, Rauscher FJ 3rd, Dressler GR. Repression of Pax-2 by WT1 during normal kidney development. Development 1995; 121:867-75.

22. Dressler GR, Woolf AS. Pax2 in development and renal disease. Int J Dev Biol 1999;43:463-8.

23. Torban E, Eccles MR, Favor J, Goodyer PR. PAX2 suppresses apoptosis in renal collecting duct cells. Am J Pathol 2000;157:833-42.

24. Mrowka C, Schedl A. Wilms' tumor suppressor gene WT1: from structure to renal pathophysiologic features. J Am Soc Nephrol 2000;11:Suppl 16:S106-15.

25. Yosypiv IV. Renin-angiotensin system in ureteric bud branching morphogenesis: insights into the mechanisms. Pediatr Nephrol 2011;26: 1499-512.

26. Zhang SL, Guo J, Moini B, Ingelfinger JR. Angiotensin II stimulates Pax-2 in rat kidney proximal tubular cells: impact on proliferation and apoptosis. Kidney Int 2004;66:2181-92.

27. Yosypiv IV, Schroeder M, El-Dahr SS. Angiotensin II type 1 receptor-EGF receptor cross-talk regulates ureteric bud branching morphogenesis. J Am Soc Nephrol 2006;17:1005-14.

28. Nigam SK, Shah MM. How does the ureteric bud branch? J Am Soc Nephrol 2009;20:1465-9.

29. Sweeney D, Lindström N, Davies JA. Developmental plasticity and regenerative capacity in the renal ureteric bud/collecting duct system. Development 2008;135:2505-10.

30. Adzick NS, Harrison MR, Flake AW, et al. Development of a fetal renal function test using endogenous creatinine clearance. J Pediatr Surg 1985;602:7-20. 